\title{
CORRESPONDENCE
}

\section{European money could end delays on essential facilities}

I endorse the proposal for the European Union (EU) to increase its financial support of large European research facilities (Nature 464, 659; 2010). But it would be better to concentrate this on a few essential facilities, rather than using the money to subsidize the running costs of hundreds of different ones.

Essential facilities include those that are crucial for establishing and maintaining Europe's position at the forefront of international science, but are too large and expensive for individual countries to build and operate alone. Europe has no more than a handful today, all disciplines included. Decisionmaking about the creation, location and financial structure of these essential facilities is currently too slow and inefficient.

Years of delay could be prevented by strong financial support from the EU. This would amount to a sizeable fraction of the construction costs of each facility. It would be granted on the basis of sound and authoritative scientific judgement, conditional on rapid decision-making and implementation.

Concentrating funds in this way would allow the deployment of even better equipment and user support, with tangible benefit to the European science enterprise.

Massimo Altarelli European X-Ray Free-Electron Laser Facility (XFEL), Notkestrasse 85, 22607 Hamburg, Germany

e-mail: massimo.altarelli@xfel.eu

\section{Independent research offers freedom and opportunities}

Andrea Schweitzer makes a strong case, in her Prospects article, for independently pursuing science outside academia (Nature 464, 945; 2010). Another bonus is the freedom to pursue lines of inquiry that run counter to prevailing paradigms.

It is not easy for a researcher to question accepted dogma, particularly if one is dependent on the good will of search committees and grant-awarding agencies. These often contain individuals with a vested interest in the status quo.

There are several lines of investigation open to an independent scholar with limited resources. These include theoretical studies, for challenging existing theories and creating new ones; reanalysis of previously published results, to investigate alternative conclusions; computer simulations, particularly useful for quantitative evaluation of theories; and metastudies or literature reviews, to find out the extent to which the overall data support a generally accepted interpretation.

To be free to think and write without consideration for funding or promotion is a substantial benefit. Such research is not necessarily easy - for example, an independent affiliation may be an obstacle to publication. But it does allow the exploration of wider areas of research that are not generally pursued by those constrained in academic careers. Bernt Christian Skottun Ullevålsalleen 4C, 0852 Oslo, Norway e-mail: berntskottun@yahoo.com

\section{Earthquake defence and the price of a telescope}

We welcome the European Southern Observatory's decision to site the European Extremely

Large Telescope (E-ELT) at Cerro Armazones in Chile.

In his Correspondence on the subject, Francisco Sánchez argues that the high seismicity of Chile's Armazones region could damage the telescope's optical systems (Nature 464, 977; 2010). However, he is misinformed about the vulnerability of telescopes under seismic conditions and about the costs of preventing possible damage to them.

There have been several large earthquakes in northern Chile during the past 40 years, the most recent being the Maule earthquake on 27 February 2010 None of the observatories including the Very Large Telescope at Paranal - suffered any significant damage.

Seismic isolation reduces structural accelerations and forces by 6-8 times compared with those affecting a conventional structure. To guarantee full operational continuity for the E-ELT, approximately 52 seismic isolators will be required, each one costing up to US\$10,000 a total of half a million dollars. This is a long way from doubling the cost of the structure (€1.1 billion; US $\$ 1.5$ billion), as Sánchez claims.

The costs of controlling the effects of seismicity are negligible in comparison with those of constructing the E-ELT and its instrumentation.

Leopoldo Infante Chilean Astronomical Society and Departamento de Astronomía y Astrofísica, P. Universidad Católica de Chile, Vicuña Mackenna 4860,

Santiago, Chile

e-mail: linfante@astro.puc.cl Juan Carlos de la Llera Earthquake Engineering Research Institute and Departamento de Ingeniería Estructural y Geotécnica, P. Universidad Católica de Chile

\section{Questionable value of planting thirsty trees in dry regions}

To alleviate land degradation, China's government is investing huge amounts of money in afforestation. But long-term results indicate that these projects could be exacerbating environmental degradation in arid and semi-arid regions, damaging soil ecosystems, reducing vegetation diversity and cover, and increasing water shortages (S. Cao Environ.
Sci. Technol. 42, 1826-1831; 2008).

Although afforestation

is potentially important for environmental restoration, China's policy does not take into account the fact that afforestation of arid regions is primarily water-limited, with drought being a major constraint on forest growth. Most of the restoration programmes - including the Three Norths shelter-forest system and regional sand control programmes involve planting trees in areas where annual precipitation is less than $\mathbf{4 0 0}$ millimetres. In the semi-arid Loess Plateau, water yields have dropped by $30-50 \%$ and vegetation cover has decreased by $6.1 \%$ as a result (G. Sun et al. J. Hydrol. 328, 548-558; 2006).

The Chinese government has not properly considered local environmental conditions, and this has led to over-planting of trees and the use of unsuitable species. For example, the excessive demand for water by the tree Populus tremula, which accounts for almost half of China's reforestation (J. Liu et al. Proc. Natl Acad. Sci. USA 105, 9477-9482; 2008), negates any potential environmental benefits.

Alongside afforestation, managers should be recreating natural ecosystems to help combat desertification. Largescale, long-term research is urgently needed to supply data to support a more flexible restoration policy.

Shixiong Cao, Guosheng Wang College of Economics and Management, China Agricultural University, No. 2 Yuan Ming Yuan West Road, Haidian District, 100094, Beijing, China e-mail: shixiongcao@126.com Li Chen Water and Soil Conservation Institute of Yan'an City, 716000 Shaanxi, China

Contributions may be submitted to correspondence@nature. com after consulting the author guidelines at go.nature.com/ cMCHno. Readers can also now comment online on anything published in Nature: www.nature. com/nature. 